Instructions for authors, subscriptions and further details:

http://rasp.hipatiapress.com

\title{
A Perceptual Approach to Aging: Latent Aging.
}

Fahri Özsungur

Adana Science and Technology University (Turkey)

Date of publication: July $30^{\text {th }}, 2020$

Edition period: July 2020- January 2021

To cite this article: Özsungur, F. (2020). COVID-19: A Perceptual

Approach to Aging: Latent Aging. Research on Ageing and Social Policy, 8(2), 169-191. http://10.4471/rasp.2020.4836

To link this article: http://dx.doi.org/10.447/rasp.2020.4836

\section{PLEASE SCROLL DOWN FOR ARTICLE}

The terms and conditions of use are related to the Open Journal System and to Creative Commons Attribution License (CCAL). 


\section{A Perceptual Approach to Aging: Latent Aging}

Fahri Özsungur

Adana Science and Technology University

(Received: 29 October 2019; Accepted: 28 February 2020; Published: 30 July 2020)

\section{Abstract}

This study is a review article. Gerontology literature was reviewed and issues of latent aging were systematically formed. According to the results of the study, latent aging consists of perceptual diagnosis, research, adoption, and reactive actions. Reactive actions include the social, psychological and physical effects of latent aging. The social effects of latent aging are the decline of social relations and social isolation. Depression, stress, anxiety, traumas and cognitive decline are among the psychological effects. Chronic musculoskeletal pain, sleep disorders, premature mortality, and suicidal ideation were determined as physical effects. The detection of latent aging is important in the prevention of chronic diseases. It was revealed that latent aging has the following four main processes: perceptual diagnosis and coding, research and comparison, adoption and reactive actions. Furthermore, this aging approach has three significant effects: social, psychological and physical.

Keywords: latent aging, imitator of aging, aging process, gerontology 


\section{Un Enfoque Perceptual de la Edad: Envejecimiento Latente}

Fahri Özsungur

Adana Science and Technology University

(Recibido: 29 octubre 2019; Aceptado: 28 febrero 2020; Publicado: 30 julio 2020)

\section{Resumen}

En el presente artículo se presenta una revisión. Se revisó la literatura de gerontología y se concretaron sistemáticamente los problemas de envejecimiento latente. Según los resultados del estudio, el envejecimiento latente consiste en el diagnóstico perceptivo, investigación, adopción y acciones reactivas. Las acciones reactivas incluyen los efectos sociales, psicológicos y físicos del envejecimiento latente. Los efectos sociales del envejecimiento latente son la disminución de las relaciones sociales y el aislamiento social. La depresión, el estrés, la ansiedad, los traumas y el deterioro cognitivo se encuentran entre los efectos psicológicos. El dolor musculoesquelético crónico, los trastornos del sueño, la mortalidad prematura y la ideación suicida se determinaron como efectos físicos. La detección del envejecimiento latente es importante en la prevención de enfermedades crónicas. Se reveló que el envejecimiento latente tiene los siguientes cuatro procesos principales: diagnóstico y codificación perceptual, investigación y comparación, adopción y acciones reactivas. Además, este enfoque de envejecimiento tiene tres efectos significativos: social, psicológico y físico.

Palabras clave: envejecimiento latente; imitador del envejecimiento; proceso de envejecimiento; gerontología 


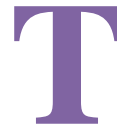

oday, the elderly population is increasing with the advances in medicine and technological innovations (Chatterjee \& Price, 2009). Technological innovations have led to innovation in the field of medicine and crucial advances have been made in coping with diseases (Topo, 1998; Dishman et al., 2004). The development of communication technology has brought smartphones and the internet to social life (Kurniawan, 2006). Thanks to smartphones and the internet, individuals can shop online without leaving their homes, provide social interaction, perform banking transactions and perform their daily tasks (Bouma, 1992; Uchida et al. 2001; Shizuka, 2006). These facilities provide easy access to useful health information and practices. Social interaction has increased, and individuals have informed of health developments and new techniques (Adler, 1996; Baldwin, 2002). Important steps have been taken for healthy aging and the elderly population has gradually increased (Barr, 2002). Thus, studies in the field of aging have increased and especially social, cognitive and psychological researches have emerged. Studies have shown that although aging is a multifaceted process, it is under perceptual effects (Cassidy et al., 2019; Hooker et al., 2019; Smith \& Bryant, 2019; Gire, 2019). In this context, the concept of "latent aging" has been proposed in the literature (Özsungur, 2019a; Özsungur, 2019b). This concept requires the study of the effects of perception and cognitive effects on the aging process.

In the aging process, the joint and muscle structure weakens, loneliness and isolated thinking dominate the psychological aspect. The individual who is exposed to these severe consequences slowly withdraws from life. S/he gradually loses his/her physical abilities and social strength by losing the activeness. Wrinkles occur on the skin depending on the aging. These wrinkles create a judgment about the fact that the individual is starting to get older. The individual begins to define her/himself as old in this process. Individuals may feel old when they begin to see some of the conditions defined for the elderly. This perceptual situation also applies to individuals under 65 years of age. This whole process creates latent aging. Latent aging is a type of aging that appears under the cognitive and psychological effects revealed by Özsungur (2019b) for the first time in the literature. 
The perception of aging can be psychological or physical. It is not enough for an individual to enter aging syndrome in the life cycle for latent aging. Significant findings should be obtained by the individual with regard to enter into the aging process in terms of physical and psychological and social aspects. These findings are the sum of beliefs and thoughts that are perceptually a sign of aging. Therefore, there are important differences between latent aging and active aging, healthy aging, premature aging.

The active aging approach suggests the active participation of individuals in life and increasing activities (Daatland, 2005). According to this approach, as individuals participate in social life and work life, they get older successfully (Joung \& Miller, 2007). In latent aging, as the individual withdraws from active participation in social and business life due to physical decline, the perception of aging emerges with the negative emotion. Active aging predicts active participation of the individual in life, while latent aging predicts withdrawal from active participation.

Healthy aging is a type of aging that involves the condition of physically healthy, strong muscle and bone structure. Skin wrinkles do not begin to occur or are less than usual according to this approach (Depp \& Jeste, 2006; Morrow-Howell, 2003). Latent aging is the exact opposite of this aging type. The health status required by the healthy aging approach is in perceptually declining process in terms of latent aging. For instance, some significant functional difficulties emerge such as slight wrinkles on the skin, fatigue while working, and feeling weak. Aging affects the individual not only in terms of health but also in social and psychological aspects (Bowling \& Paul, 2005; House \& Landis, 1988; Bengtson et al., 2005).

Latent aging develops differently from psychological and cognitive processes. The perception of aging under the influence of psychological disorders and latent aging is different in terms of their functions and features. Cognitive/psychological aging focuses on the consequences of aging that occur under the physiological, environmental or biological effects of an individual (Willis, 1996; Diehl et al., 1995). However, the latent aging approach investigates the causes of aging along with the results. Furthermore, latent aging emphasizes the importance of the perception of the individual and a positive lifestyle. The individual makes a judgment about the aging in the perceptual process by evaluating environmental and self-related factors together over time in latent aging. 
While the cognitive/psychological aging approach is a syndrome due to the increase of age, latent aging occurs as a result of negative effects caused by psychological and perceptual errors (Schaie \& Willis, 1986; Baltes \& Lindenberger, 1988).

Cognitive aging is the decline of memory and processing speed in the aging process (Salthouse, 2019; Aghamohammadi - Sereshki et al., 2019). Processing speed, conceptual reasoning, and memory are important skills of the individual in the aging process. The regression of these abilities lead to cognitive decline (Mahoney et al., 2019). Individuals' abilities of problemsolving ability, reasoning, manipulating are associated with crystallized and fluid intelligence. Individuals use attention and language skills in their interaction with their environment (Franceschi et al., 2019; Cox et al., 2019). They record the information obtained from the environment in their memory (Haines et al., 2019; Hülür et al., 2019). Information obtained by visual memory becomes functional through reasoning and visuospatial abilities (Komanduri et al., 2019). These abilities, which are also effective in the creativity of individuals, are important in the context of performing daily activities, social adaptation and mental health (Yu et al., 2019).

In premature/ progeroid aging, the individual falls under the influence of medical aging (Eriksson et al., 2003; Gilchrest, 1981; Yu et al., 1996). Premature aging is a type of aging that imitates physiological aging at an early age. This syndrome is called Hutchinson-Gilford Progeria Syndrome (HGPS) and Werner syndrome (WS) (Hegele, 2003; Coppede, 2012). The individual falls under the influence of this involuntary disease due to the effects of the progeroid aging disease, not the symptoms of aging (Coppede, 2012; Feinberg, 2007; Kaminsky et al., 2009). The individual experiences latent aging syndrome as a result of adopting this situation by associating some physical, social and psychological changes that have been detected on her/himself (without premature aging disease) with aging. This syndrome occurs in four basic processes: perceptual diagnosis, research, adoption, and reactive actions. When these processes are evaluated together, the study aims to reveal the processes of latent aging and to explain its effects. In this context, the social, psychological and physical effects of latent aging were explained. 


\section{Research Metodology}

This study was formed by a systematic review method (Robinson \& Lowe, 2015). Identification, review, analysis, summarization, discussion, and presentation processes were followed respectively (Uman et al., 2008). The research question (What are the process of latent aging and its effects in the context of the perceptual approach?) was determined. Based on this question, a theoretical framework was formed. While constituting the titles, the framework and the obtained information were coded (Petticrew \& Roberts, 2008). The issues of perceptual diagnosis and coding, research and comparison, adoption, reactive actions, social effects of latent aging, psychological effects of latent aging, physical effects of latent aging were discussed respectively (Uman, 2011). The study title, headings, and subheadings were evaluated in the context of their consistency.

\section{Perceptual Diagnosis and Coding}

Perceptual diagnosis is an individual's identification of the information learned about aging, and this information is attributed to the meaning of aging. The individual chronologically prioritizes the information he/she has gained with cognitive reasons and consequences. Information about aging is collected from the environment. In this stage, the individual performs the recording process related to the information acquired. The memorized information is then stored for significant comparison and judgment.

The physical, social, psychological and mental states of the individual, the change during the year and comparison of the previous year are coded in memory. According to the information obtained from the environment, the change of the elderly person according to the years and the last situation reached are memorized. However, errors may occur in perceptual diagnosis. The individual can encode contradictory information into memory by comparing the information obtained from the environment with different samples. Some symptoms of aging may occur in different ways between individuals. In this case, perception occurs according to the individual's belief at the time of coding under the psychological and physical effects of the individual. Factors such as culture, oppression, family, society, and health can have an impact on the individual's perceptions. 
An individual with positive thinking can imitate someone who does not show symptoms of aging despite years. An individual who is in a negative state can imitate someone showing symptoms of aging. Affective states such as positive or negative mood, happiness or unhappiness, satisfaction or discontent affect the individual's behavior and perception (Compeau, 1999). Positive psychology increases the social participation of older individuals and affects their decision to stay in the workplace (Armstrong-Stassen \& Schlosser, 2011). For these reasons, the psychological state is effective in the perception of the individual.

Coding is the process of classifying and recording the information obtained. The personal characteristics, social relations, physical appearance, health status of a neighbor, which has been recognized for many years, are examples of the obtained information. If the follower and the followee live under the same conditions, no difference emerges in the classification of the cases observed. If the follower is under negative impacts and the followee is under positive impacts, perception of justice predominates and the situation (the phenomenon of aging) can be perceived as the fault of the followee. In this case, the follower starts to receive information from individuals under different conditions related to aging. Coding is the process of classifying and recording the information obtained. The personal characteristics, social relations, physical appearance, health status of a neighbor, which has been recognized for many years, are examples of the obtained information. If the follower and the followee live under the same conditions, no difference emerges in the classification of the cases observed. If the follower is under negative impacts and the followee is under positive impacts, perception of justice predominates and the situation (the phenomenon of aging) can be perceived as the fault of the followee. In this case, the follower starts to receive information from individuals under different conditions related to aging. If the follower is under positive and the followee is under negative effects, the sense of compassion dominates and the current state (the phenomenon of aging) can be perceived as the error of factors except for the individual. In this case, the follower starts to receive information from individuals under different conditions related to aging. The information obtained from individuals who have the same effect level as the follower is classified and coded under the phenomenon of aging. 


\section{Research and Comparison}

The individual starts research to confirm that s/he thinks that the information gained is related to aging. The information and findings obtained are compared with the information that the individual makes sense. Each new phenomenon on the same subject is compared with the past. At this stage, the information stored in the memory is compared with the information obtained from the environment. The coded information about aging is chronologically compared with the information stored in memory. During the comparison, all previous information about aging is recalled vis-à-vis their classes. This operation is performed by associative addressing (Powers, 2005). The recalled information is classified according to its similarity. First, the cases in which social, physical, mental, psychological and similar declines occur depending on the increase of age are considered. In which individuals and how these phenomena occur are recalled. In the cognitive process, the changes experienced by each individual in the aging process are considered in general and comparisons are realized between individuals. Similar findings obtained in the comparisons make the individual to have an idea about the perception of aging. However, this idea must be adopted for latent aging.

Information is perceived by five senses and is included in the cognitive process. The information included in the cognitive process is encoded as perceived. A heard word is included in the hearing coding. A visually coded information is evaluated differently according to the information heard in the comparison. The different evaluation of the information is important for obtaining meaningful and consistent results of the coding. If the same coding is done, each coding will be of the same importance, so the inferences may be wrong. The coding of information is important for research and comparison.

\section{Adoption}

Adoption is a perceptual acceptance of a thought, phenomenon, object or action in the cognitive process. Adoption can result in behavior or inaction (Sprenger \& Dougherty, 2012; Sprenger \& Dougherty, 2006; Frederick, 2005). If the individual is aware of what happens in the cognitive process, it 
is possible to foresee the metacognitive process (Meichenbaum, 1985). The individual with metacognition reveals the ability to understand and learn, control and manipulate (Schraw \& Dennison, 1994; Pressley et., 1987; Borkowski et al., 1987; Flavell, 1979). The individual becomes aware of the cognitive process by controlling the information s/he understands or learns. The control allows the phenomenon to be adopted or rejected in the assessment of the cognitive process.

As a result of the information obtained regarding aging confirming each other, the individual develops the behavior of adopting the phenomenon of aging. However, the individual begins to experience some problems in the adaptation process with the environment due to the acceptance of behavior when the sense of taking over aging her/himself emerges. Even though the individual has accepted the aging at this stage, she/he may exhibit the behavior of not tolerating the negative criticism of the social environment. At this stage, the individual is exposed to the effects of aging perception before reaching the usual limit of aging. The individual who is exposed to this psychological and mental state may begin to withdraw from life at an early age by moving away from sociality. Although the physical symptoms of aging do not appear completely in latent aging, psychological well-being, self-confidence, and self-fulfillment may be negatively affected. The emergence of the latent aging perception by adoption shows negative effects due to psychological and perceptual errors.

Adoption of adoption behavior by active actions is essential in terms of interaction with the environment. As a result of this interactive adoption behavior, the individual reveals that he/she adopts or accepts the perception of aging. The thoughts about the perception of aging are declared to the other side in the conversation environment between individuals. However, this declaration is realized for the sharing of thought, instead of getting an idea from the other party about the accuracy of perception. It may be desirable to obtain a useful view from other individuals about the negative effects of aging in interactive adoption behavior. Realizing the adoption behavior by inactivity is noninteractive adoption. The individual does not want to reveal the perception of aging and share it with other individuals. The individual wants to experience the effects of aging in his/her world in this process. It is perceived that social support will not be beneficial in terms 
of aging by the individual. In such cases, the individual may exhibit an introverted personality.

\section{Reactive Actions}

Reactive actions are the process in which latent aging emerges completely. At this stage, it appears with the effects of latent aging. The effects of old age through direct or indirect actions are observed in the individual. Direct actions develop when an individual's perception of aging directly declares to the external environment. In indirect actions, symptoms of latent aging may be observed in the individual, but the individual does not declare the perception of the aging to the external environment. Both actions are a period in which the social, psychological and physical effects of latent aging emerge.

\section{Social Effects of Latent Aging}

Latent aging is an essential output of people's perceptions as psychological, individual, medical, environmental and behavior regarding the aging process. The individual's acceptance of the aging perception error in the cognitive process may cause serious social problems. An individual who has the perception that he/she gets old can weaken social relations by reducing social participation. This situation can be realized by the individual her/himself or the negative effects of the perception of aging on the people that may cause social isolation. The older individual, who reveals that $\mathrm{s} / \mathrm{he}$ does not enjoy life, may change the thoughts of close friends and his/her family regarding her/himself by exhibiting negative behaviors in contrast to previous behaviors negatively. Trying to adapt her/his misperception to close friends who do not see themselves as old can cause isolation. Social isolation causes the individual to move away from social interaction and loneliness. Social isolation is an essential factor that negatively affects the health of the elderly (Cattan et al. 2005; Nicholson, 2012). In order to prevent the health of the individual to be negatively affected during the aging process, it is necessary to avoid the effects of social isolation. 


\section{Psychological Effects of Latent Aging}

The effects of social isolation and loneliness as a result of latent aging focus on three main factors: psychological, behavioral and physical. The individual who believes that $\mathrm{s} / \mathrm{he}$ is getting older starts to change her/his way of life by withdrawing from social relations. Depression, stress, anxiety, traumas, and cognitive decline are experienced psychologically due to loneliness (Frumkin et al., 2004; Hill, 2009; Steptoe et al., 2012). These negative effects cause the weakening of physical mobility and problems in nutrition and drug use (Mayer et al., 2009). These negative developments may cause the individual to experience significant discomfort in the heart, stomach, vision, muscle and chronic pain (Luanaigh \& Lawlor, 2008; Tivis et al., 2011; Caspi et al., 2006; Landeiro et al., 2016; Courtin \& Knapp, 2015). Behaviors can be exhibited linked to the sense of loneliness such as acting as a patient even though he/she is not sick to attract attention, attending to the emergency department, call an ambulance, asking for help (Landeiro et al., 2016). Latent aging may lead to the maintenance of bad habits or the emergence of new bad habits (Golden et al., 2009). Negative effects such as the emotion of guilt, injustice, and intolerance are the states that may occur with latent aging.

\section{Physical Effects of Latent Aging}

The psychological effects of latent aging reduce social commitment and cause loneliness. This effect may cause deterioration of physical and mental health (Parrish et al., 2008; Sturgeon \& Zautra, 2016). One of these health problems is chronic musculoskeletal pain. This pain appears in the form of muscle atrophy and related depression, pain sensation, and fatigue occurring in the musculoskeletal system (Veronese et al., 2017). Poor social relations, loneliness, lack of interest can lead to sleep disorders, premature mortality, and suicidal ideation (Smith et al., 2004; Brandstetter, 2017).

In the process of healthy aging, psychological resistance is an important factor in coping with complicated problems. Problems in perception and cognitive processes and misconceptions affect this psychological resistance. The individual may feel such emotions as anxiety and fear during his/her life 
cycle under the influence of latent aging (Asmundson et al., 2012). Fear and panic can cause involuntary behavior (Lucchetti et al., 2012). Thus, the individual transforms the idea that he/she gets older in the perceptual process into reactive actions. These reactive actions may result in chronic diseases.

\section{Discussion}

Aging is under social, physical, psychological, psychosocial and biological influences (Miller et al., 2004). Health is an important driving force for the individual to hold onto life (Rowe \& Kahn, 1987; Rowe \& Kahn, 1997; Rubinstein et al., 1992; Schulz \& Heckhausen, 1996). The individual can be motivated through social networks and stabilize the complex emotions s/he experiences in her/his cognitive processes (Rutter et al., 2019; Livingstone \& Isaacowitz, 2019; Carstensen et al., 2003). However, psychology is a latent factor that can affect all of these factors. Psychological factors have a positive effect on self-esteem and coping with depression and anxiety (Kunzmann, 2019; Wang et al. 2019; O'Brien Cousins, 2001; O'Brien Cousins, 2003). Psychology is an important but complex factor affecting mental processes. Studies have provided evidence that psychology has a positive effect on depression and mental health (Barbour \& Blumenthal, 2005; Kane et al., 2006; Cooper \& Feldman, 2019; Rutter et al., 2019; Weissberger et al., 2019). Psychological resistance and flexibility form the basis of the theory of active aging. Richardson (2002), in a study on active aging, emphasized that it is necessary for active aging to conduct research in order to hold on to life, to face the risks of life and to provide the necessary conditions for a healthy life (Zahodne et al., 2019; Eismann et al., 2019; Richardson, 2002). However, the emergence of aging via imitation in terms of perception has not been studied in the literature.

In this study, the subject of latent aging, which was introduced to the literature for the first time, was examined with a perceptual approach. Perception significantly affects an individual's psychological state in the context of environmental influences. The fact that aging is a perceptual process is important in terms of psychological, social and physical consequences. There is no study in the literature that aging has a latent effect through a perceptual process. Although this deficiency in the literature shows the strength of the study, it should be supported by empirical studies. 
Findings that are not supported by empirical findings constitute the limitation of the study. According to the results of the study, latent aging consists of perceptual diagnosis, research, adoption, and reactive actions. Reactive actions include the social, psychological and physical effects of latent aging. The social effects of latent aging are the decline of social relations and social isolation. Depression, stress, anxiety, traumas and cognitive decline are among the psychological effects. These psychological influences may lead to the emergence of new bad habits. The associations between latent aging and negative psychological effects such as the emotion of guilt, injustice, and intolerance of latent aging should be investigated. Latent aging also reveals physical effects. Chronic musculoskeletal pain, sleep disorders, premature mortality, and suicidal ideation were determined as physical effects. Therefore, the detection of latent aging is important in the prevention of chronic diseases.

Latent aging was first proposed by Özsungur (2019b). According to the author's findings, latent aging was associated with palliative diseases, physical changes, and chronic pain. According to further findings, latent aging showed the symptoms of psychological (stress, anxiety, nervousness, burnout, tiredness, fatigue), physical (arthritis pain, unjustified pain), medical (digestive and stomach diseases, high blood pressure, systemic lupus erythematosus, nephrotic syndrome).

\section{Conclusions and Recommendations}

According to the results of the study, it was determined that latent aging took place in a certain process and this process emerged as perceptual diagnosis, research, adoption, and reactive actions. Besides, this type of aging has physical, psychological and social effects on individuals. Latent aging is important for the individual's adaptation to the aging process. Therefore, the perceptual effects of latent aging should be considered by individuals. In this context, awareness training is recommended.

The perceptual process of latent aging and the individual's perception of aging is an important issue to be investigated. In particular, studies on imitating diseases will help to reveal the perception of aging. For future studies, it is recommended to investigate the association between palliative 
diseases and imitation ability. Considering the importance of psychological and social effects of perception, clinical research on the perception of aging should be increased. Especially, considering the psychological effects, investigating the association between negative psychological factors and latent aging will contribute to the literature. It is important to carry out these studies by taking into consideration the processes and recommendations mentioned in the study.

\section{References}

Adler, R. P. (1996). Older adults and computers: Report of a national survey. SeniorNet.

Aghamohammadi-Sereshki, A., Hrybouski, S., Travis, S., Huang, Y., Olsen, F., Carter, R., ... \& Malykhin, N. V. (2019). Amygdala subnuclei and healthy cognitive aging. Human brain mapping, 40(1), 34-52. https://doi.org/10.1002/hbm.24353

Armstrong-Stassen, M., \& Schlosser, F. (2011) Perceived Organizational Membership and The Retention of Older Workers. Journal of Organizational Behavior, 32, 319344. https://doi.org/10.1002/job.647

Asmundson, G.J., Parkerson, H.A., Petter, M., \& Noel, M. (2012). What is the role of fear and escape/avoidance in chronic pain? Models, structural analysis and future directions. Pain Manag, 2, 295-303. https://doi.org/10.2217/pmt.12.15

Baldwin, C. L. (2002). Designing in-vehicle technologies for older drivers: Application of sensory-cognitive interaction theory. Theoretical Issues in Ergonomics Science, 3, 307-329. https://doi.org/10.1080/1463922021000009029

Baltes, P. B., \& Lindenberger, U. (1988). On the range of cognitive plasticity in old age as a function of experience: 15 years of intervention research. Behavior Therapy, 19(3), 283-300.

Barbour, K.A., \& Blumenthal, J.A. (2005). Exercise Training and Depression in Older Adults. Neurobiology of Aging, 26(1), 119-123. https://doi.org/10.1016/j.neurobiolaging.2005.09.007

Barr, R. A. (2002). More road to travel by: Implications for mobility and safety in late life. Gerontechnology, 2, 50-54. 
Bengtson, V. L., Putney, N., \& Johnson, M. (2005). The problem of theory in gerontology today. In M. Johnson (Ed.), The Cambridge handbook of age and ageing, (pp. 3-21). Cambridge University Press.

Borkowski, J., Carr, M., \& Pressely, M. (1987). "Spontaneous” strategy use: Perspectives from metacognitive theory. Intelligence, 11, 61-75.

Bouma, H. (1992). Gerontechnology: Making technology relevant for the elderly. In Bouma, H., Graafmans, J. A. M. (Eds.), Gerontechnology (pp. 1-5). IOS Press.

Bowling, A., \& Paul, D. (2005). What is successful ageing and who should define it?. BMJ, 331, 1548-1551. https://doi.org/10.1136/bmj.331.7531.1548

Brandstetter, S., Riedelbeck, G., Steinmann, M., Ehrenstein, B., Loss J., \& Apfelbacher, C. (2017). Pain, social support and depressive symptoms in patients with rheumatoid arthritis: Testing the stressbuffering hypothesis. Rheumatol Int., 37, 931-936. https://doi.org/10.1007/s00296-017-3651-3

Carstensen, L.L., Fung, H.H., \& Charles, S.T. (2003). Socioemotional Selectivity Theory and The Regulation of Emotion in The Second Half of Life. Motivation and Emotion, 27(2), 103-123.

Caspi, A., Harrington, H., Moffitt, T.E., Milne, B.J., \& Poulton, R. (2006). Socially isolated children 20 years later, Archives of Pediatrics and Adolescent Medicine, 160(8), 805-811. https://

doi.org/10.1001/archpedi.160.8.805

Cassidy, B. S., Hughes, C., Lanie, S. T., \& Krendl, A. C. (2019). Effects of executive ability on bias and ingroup perceptions in aging. Psychology and aging. https://doi.org/10.1037/pag0000420

Cattan, M., White, M., Bond, J., \& Learmouth, A. (2005). Preventing social isolation and loneliness among older people: a systematic review of health promotion interventions. Ageing \& Society, 25(1), 4167. https://doi.org/10.1017/S0144686X04002594

Chatterjee S., \& Price A. (2009). Healthy Living with Persuasive Technologies. Framework, Issues and hallenges. J Am Inform Assoc., 16(2), 171-8. https://doi.org/10.1197/jamia.M2859 
Compeau, D., Higgins, C., \& Huff, S. (1999). Social Cognitive Theory and Individual Reactions to Computing Technology: A Longitudinal Study. MIS Quarterly, 23(2), 145-158.

Cooper, J., \& Feldman, L. A. (2019). Does cognitive dissonance occur in older age? A study of induced compliance in a healthy elderly population. Psychology and Aging, 34(5), 709-713.

https://doi.org/10.1037/pag0000338

Coppede, F. (2012). Premature aging syndrome. Adv Exp Med Biol., 724, 317-31. https:// doi.org/10.1007/978-1-4614-0653-2_24

Courtin, E., \& Knapp, M. (2015). Social isolation, loneliness and health in old age: a scoping review. Health and Social Care in the Community, 25(3), 799-812. https://doi.org/10.1111/hsc.12311

Daatland, S. (2005). Quality of Life and Ageing. M. Johnson (Ed.). The Cambridge Handbook of Age and Ageing (pp. 371-377). Cambridge University Press.

Depp, C. A., \& Jeste, D. V. (2006). Definition and predictors of successful aging: a comprehensive review of larger quantitative studies. American Journal of Geriatric Psychiatry, 14(1), 6-20. https://doi.org/10.1097/01.JGP.0000192501.03069.bc

Diehl, M., Willis, S.L., \& Shaie, K.W. (1995). Everyday problem solving in older adults: observational assessment and cognitive correlates. Psychol Aging, 10, 478-491.

Diehl, M., Marsiske, M., Horgas, A., Rosenberg, A., Saczynski, J.S., \& Willis, S.L. (2005). The revised observed tasks of daily living: a performance-based assessment of everyday problem solving in older adults. J Appl Gerontol. 24, 211-230.

https://doi.org/10.1177/0733464804273772

Dishman, E., Matthews J., \& Dunbar-Jacob, J. (2004). Everyday Health: Technology for Adaptive Aging. In: National Research Council (US) Steering Committee for the Workshop on Technology for Adaptive Aging; R.. Pew \& S.B. Van Hemel, editors. Technology for Adaptive Aging. National Academies Press (US).

Cox, S. R., Ritchie, S. J., Allerhand, M., Hagenaars, S. P., Radakovic, R., Breen, D. P., ... \& Deary, I. J. (2019). Sleep and cognitive aging in the eighth decade of life. Sleep, 42(4), zsz019. https:// doi.org/10.1093/sleep/zsz019 
Eismann, M., Verbeij, T., \& Henkens, K. (2019). Older workers' plans for activities in retirement: The role of opportunities, spousal support, and time perception. Psychology and Aging, 34(5), 738-749. https:// doi.org/10.1037/pag0000377

Eriksson, M, Brown, W.T., Gordon, L.B., Glynn, M.W., Singer, J., Scott, L., Erdos, M.R., Robbins, C.M., Moses, T.Y., Berglund, P., Dutra, A., Pak, E., Durkin, S., Csoka, A.B., Boehnke, M., Glover, T.W., \& Collins, F.S. (2003). Recurrent de novo point mutations in lamin A cause Hutchinson-Gilford progeria syndrome. Nature, 423(6937), 293-298. http://dx.doi.org/10.1038/nature01629

Feinberg, A.P. (2007). Phenotypic plasticity and the epigenetics of human disease. Nature, 447, 433-440.

http://dx.doi.org/10.1038/nature05919

Flavell, J. H. (1979). Metacognition and cognitive monitoring: A new area of cognitive-developmental inquiry. AmericanPsychologist, 34, 906-911.

Franceschi, C., Garagnani, P., Gensous, N., Bacalini, M. G., Conte, M., \& Salvioli, S. (2019). Accelerated bio-cognitive aging in Down syndrome: State of the art and possible deceleration strategies. Aging cell, 18(3), e12903. http://dx.doi.org/10.1111/acel.12903

Frederick, S. (2005). Cognitive reflection and decision making. J. Econ. Perspect. 19, 25-42.

Frumkin, H., Frank, L.D., \& Jackson, R. (2004). Urban Sprawl and Public Health: Designing, Planning and Building for Healthy Communities. Island Press, Washington, DC.

Gilchrest, B.A. (1981). Premature aging syndromes affecting the skin. Birth Defects Orig Artic Ser., 17(2), 227-41.

Gire, J. T. (2019). Cultural variations in perceptions of aging. CrossCultural Psychology: Contemporary Themes and Perspectives, 216240. https://doi.org/10.1002/9781119519348.ch10

Golden, J., Conroy, R.M., Bruce, I., Denihan, A., Greene, E., Kirby, M., \& Lawlor, BA. (2009). Loneliness, social supports, mood and wellbeing in community-dwelling elderly, International Journal of Geriatric Psychiatry, 24(7), 694-700. https://doi.org/10.1002/gps.2181 
Gurera, J. W., \& Isaacowitz, D. M. (2019). Emotion regulation and emotion perception in aging: A perspective on age-related differences and similarities. Progress in brain research, 247, 329-351. https:// doi.org/10.1016/bs.pbr.2019.02.007

Haines, S. J., Shelton, J. T., Henry, J. D., Terrett, G., Vorwerk, T., \& Rendell, P. G. (2019). Prospective Memory and Cognitive Aging. In Oxford Research Encyclopedia of Psychology. https:// doi.org/10.1093/acrefore/9780190236557.013.381

Hegele, R.A. (2003). Drawing the line in progeria syndromes. Lancet, 362, 416 - 417. https:// doi.org/10.1016/S0140-6736(03)14097-4

Hill, D.L. (2009). Relationship between sense of belonging as connectedness and suicide in American Indians. Archives of Psychiatric Nursing, 23(1), 65-74. https:// doi.org/10.1016/j.apnu.2008.03.003

Hooker, K., Mejía, S. T., Phibbs, S., Tan, E. J., \& Stevens, J. (2019). Effects of age discrimination on self-perceptions of aging and cancer risk behaviors. The Gerontologist, 59(Supplement_1), S28-S37. https:// doi.org/10.1093/geront/gny183

House, J., \& Landis, K. (1988). Social relationships and health. Science, 29, 241(4865), 540-545. https:// doi.org/10.1126/science.3399889 Joung, H.-M. \& Miller, N. J. (2007). Examining The Effects of Fashion Activities on Life Satisfaction of Older Females: Activity Theory Revisited. Family and Consumer Sciences Research Journal, 35(4), 338-356. https://doi.org/10.1177/1077727X07299992

Hülür, G., Ram, N., Willis, S. L., Schaie, K. W., \& Gerstorf, D. (2019). Cohort differences in cognitive aging: The role of perceived work environment. Psychology and aging, 34(8), 1040.

https://doi.org/10.1037/pag0000355

Kaminsky, Z.A., Tang, T., Wang, S.-C., Ptak, C., Oh GHT, Wong AHC, ... Petronis, A. (2009). DNA methylation profiles in monozygotic and dizygotic twins. Nat Genet, 41, 240 - 245. https:// doi.org/10.1038/ng.286

Kane, M.N., Lacey, D., \& Green, D. (2006). Correlates of Perceptions of Elders Suffering from Depression. Advances in Social Work, 7(1), 44-56. https://doi.org/10.18060/119

Komanduri, M., Gondalia, S., Scholey, A., \& Stough, C. (2019). The microbiome and cognitive aging: a review of mechanisms. 


\section{Psychopharmacology, 1-13. https://doi.org/10.1007/s00213-019-} 05231-1

Kunzmann, U., Schilling, O., Wrosch, C., Siebert, J. S., Katzorreck, M., Wahl, H.-W., \& Gerstorf, D. (2019). Negative emotions and chronic physical illness: A lifespan developmental perspective. Health Psychology, 38(11), 949-959. https://doi.org/10.1037/hea0000767 Kurniawan, S. (2006). An explanatory study of how old women use mobile phones. Lecture Notes in Computer Science, 4206, 105-122.

Landeiro, F., Leal, J., \& Gray, A.M. (2016). The impact of social isolation on delayed hospital discharges of older hip fracture patients and associated costs. Osteoporosis International, 27, 737-745. https://doi.org/10.1007/s00198-015-3293-9

Livingstone, K. M., \& Isaacowitz, D. M. (2019). Age similarities and differences in spontaneous use of emotion regulation tactics across five laboratory tasks. Journal of Experimental Psychology: General, 148(11), 1972-1992. https://doi.org/10.1037/xge0000556

Luanaigh, C.O., \& Lawlor, B.A. (2008). Loneliness and the health of older people. International Journal of Geriatric Psychiatry, 23, 1213-21.

Lucchetti, G., Oliveira, A.B., Mercante, J.P., \& Peres, M.F. (2012). Anxiety and fear-avoidance in musculoskeletal pain. Curr Pain Headache Rep., 16, 399-406.

Mahoney, E. R., Dumitrescu, L., Moore, A. M., Cambronero, F. E., De Jager, P. L., Koran, M. E. I., ... \& Bennett, D. A. (2019). Brain expression of the vascular endothelial growth factor gene family in cognitive aging and alzheimer's disease. Molecular psychiatry, 1-9. https://doi.org/10.1038/s41380-019-0458-5

Mayer, F.S., Frantz, C.M., Bruehlman-Senecal, E., \& Dolliver, K. (2009). Why is nature beneficial. Environment and Behavior, 41(5), 607-43.

Meichenbaum, D. (1985). Teaching thinking: A cognitive-behavioral perspective. In S. F., Chipman, J. W. Segal, \& R. Glaser (Eds.), Thinking and learning skills, 2: Research and open questions. Lawrence Erlbaum Associates.

Miller, N. B., Smerglia, V. L., \& Bouchet, N. (2004). Women's Adjustment to Widowhood: Does Social Support Matter? Journal of Women \& Aging, 16, 149-167. https://doi.org/10.1300/J074v16n03_11 
Morrow-Howell, N. (2003). Effects of volunteering on the well-being of older adults. Journal of Gerontology, 58B(3), 137-145.

Nicholson, N.R. (2012). A review of social isolation an important but underassessed condition in older adults. The Journal of Primary Prevention, 33(2-3), 137-52. https://doi.org/10.1007/s10935-0120271-2

O'Brien Cousins, S. (2001). Thinking Out Loud: What Older Adults Say About Triggers For Physical Activity. Journal of Aging and Physical Activity, 9, 347-363. https://doi.org/10.1123/japa.9.4.347 O'Brien Cousins, S. (2003). Grounding Theory in Self-Referent Thinking: Conceptualizing Motivation for Older Adult Physical Activity. Psychology of Sport and Exercise, 4, 81-100.

Parrish, C.L., Radomsky, A.S., \& Dugas, M.J. (2008). Anxiety-control strategies: Is there room for neutralization in successful exposure treatment? Clinical Psychology Review, 28(8). 1400-1412. https://doi.org/10.1016/j.cpr.2008.07.007

Powers, W.T. (2005) Behaviour: The Control of Perception. New Canann, CT.

Özsungur, F. (2019a). A Research on Relationship Between Latent Aging and Chronic Lymphocytic Thyroiditis. Biomedical Journal of Scientific \& Technical Research (BJSTR), 23(5), 17761-17763. https:// doi.org/10.26717/BJSTR.2019.23.003964

Özsungur, F. (2019b). Latent Aging. Biomedical Journal of Scientific \& Technical Research (BJSTR). 20(4)-2019. BJSTR. MS.ID.003497. https:// doi.org/10.26717/BJSTR.2019.20.003497

Petticrew, M., \& Roberts, H. (2008). Systematic reviews in the social sciences: A practical guide. John Wiley \& Sons.

Pressley, M., Borkowski, J. G., \& Schneider, W. (1987). Cognitive strategies: Good strategy users coordinate metacognition and knowledge. In R. Vasta, \& G. Whitehurst (Eds.), Annals of child development, 4, 80-129. JAI Press.

Richardson, G. E. (2002). The Meta-Theory of Resilience and Resiliency. Journal of Clinical Psychology, 58, 307-321. https://doi.org/10.1002/jclp.10020 
Robinson, P., \& Lowe, J. (2015), Literature reviews vs systematic reviews. Australian and New Zealand Journal of Public Health, 39, 103-103. https:// doi.org/10.1111/1753-6405.12393

Rowe, J.W., \& Kahn, R.L. (1987). Human aging: Usual and successful. Science, 237, 143-149.

Rowe, J.W., \& Kahn, RL. (1997). Successful aging. Gerontologist, 37, 433440.

Rubinstein, R. L., Kilbride, J. C., \& Nagy, S. (1992). Elders living alone: Frailty and the perception of choice. Aldine Transaction.

Rutter, L. A., Dodell-Feder, D., Vahia, I. V., Forester, B. P., Ressler, K. J., Wilmer, J. B., \& Germine, L. (2019). Emotion sensitivity across the lifespan: Mapping clinical risk periods to sensitivity to facial emotion intensity. Journal of Experimental Psychology: General, 148(11), 1993-2005. https://doi.org/10.1037/xge0000559

Salthouse, T. A. (2019). Trajectories of normal cognitive aging. Psychology and aging, 34(1), 17-24. https://doi.org/10.1037/pag0000288

Schaie, K.W., \& Willis S. (1986). Practical intelligence in later adulthood. In: Ed. R.J. Sternberg \& R. K. Wagner RK, Practical Intelligence (pp.236-68). University Press.

Schraw, G., \& Dennison, R. S. (1994). Assessing metacognitive awareness. Contemporary Educational Psychology, 19, 460-475.

Schulz, R., \& Heckhausen, J. (1996). A life span model of successful aging. American Psychologist, 51, 702-714.

Shizuka A. (2006). Social benefits of communication Technologies for aging Population-A case study of Japan. Asia Culture Forum, Japan, 8.

Smith, J. L., \& Bryant, F. B. (2019). Enhancing positive perceptions of aging by savoring life lessons. Aging \& mental health, 23(6), 762770. https://doi.org/10.1080/13607863.2018.1450840

Smith, M.T., Perlis, M.L., \& Haythornthwaite, J.A. (2004). Suicidal ideation in outpatients with chronic musculoskeletal pain: An exploratory study of the role of sleep onset insomnia and pain intensity. Clin J Pain, 20, 111-118.

Sprenger, A., \& Dougherty, M.R. (2012). Generating and evaluating options for decision making: the impact of sequentially presented evidence. 
190 Özsungur - A Perceptual Approach to Aging: Latent Aging

\section{J. Exp. Psychol. Learn. Mem. Cogn. 38, 550-575. \\ https://doi.org/10.1037/a0026036}

Sprenger, A., \& Dougherty, M.R. (2006). Differences between probability and frequency judgments: the role of individual differences in working memory capacity. Organ. Behav. Hum. Decis. Process, 99, 202-211.

Steptoe, A., Shankar, A., Demakakos, P., \& Wardle, J. (2012). Social isolation, loneliness and all-cause mortality in older men and women. Proceedings of the National Academy of Sciences, 110(15), 5797-801. https://doi.org/10.1073/pnas.1219686110

Sturgeon, J. A., \& Zautra, A. J. (2016). Resilience to chronic arthritis pain is not about stopping pain that will not stop: Development of a dynamic model of effective pain adaptation. In P. M. Nicassio (Ed.), Psychosocial factors in arthritis: Perspectives on adjustment and management (pp. 133-149). Springer International Publishing.

Tilvis, R. S., Laitala, V., Routasalo, P. E., \& Pitkälä, K. H. (2011). Suffering from loneliness indicates significant mortality risk of older people. Journal of aging research, https://

doi.org/10.4061/2011/534781

Topo P. (1998). Technology in everyday life and care of elderly living at home and suffering from dementia. Stud Health Technol Inform, 48, 320-323.

Uchida H., Hata Y., Matsurura S., \& Aoyama H. (2001). An evaluation of use of information technology equipment among Japanese elderly women? relation between health status and the preferred input device for the Internet. Asia Pac J Public Health, 13, 47-50.

Uman, L. S. (2011). Systematic reviews and meta-analyses. Journal of the Canadian Academy of Child and Adolescent Psychiatry = Journal de l'Academie canadienne de psychiatrie de l'enfant et de l'adolescent, 20(1), 57-59.

Wang, S., Williams, J., \& Wilmut, K. (2019). Constraints on motor planning across the life span: Physical, cognitive, and motor factors. Psychology and Aging. https:// doi.org/10.1037/pag0000408

Weissberger, G. H., Han, S. D., Yu, L., Barnes, L. L., Bennett, D. A., \& Boyle, P. A. (2019). Financial and health literacy discrepancies with 
cognition in older adults. Neuropsychology, 33(7), 975-985. https:// doi.org/10.1037/neu0000565

Willis, S.L. (1996). Everyday cognitive competence issues in elderly persons: conceptual issues and empirical findings. Gerontologist, 36(5), 595-601.

Veronese, N., Stubbs, B., Solmi, M., Smith, T.O., Noale, M., Cooper, C., \& Maggi, S. (2017). Association between lower limb osteoarthritis and incidence of depressive symptoms: data from the osteoarthritis initiative. Age and Ageing, 46(3), 470-476. https://doi.org/10.1093/ageing/afw216

Yu, C.E., Oshima, J., Fu, Y.H., Wijsman, E.M., Hisama, F., Alisch, R., Matthews, S., Nakura, J., Miki, T., Ouais, S., Martin, G.M., Mulligan, J., \& Schellenberg, G.D. (1996). Positional cloning of the Werner's syndrome gene. Science, 272(5259), 258 - 262.

Yu, J., Collinson, S. L., Liew, T. M., Ng, T. P., Mahendran, R., Kua, E. H., \& Feng, L. (2019). Super-cognition in aging: cognitive profiles and associated lifestyle factors. Applied Neuropsychology: Adult, 1-7. https://doi.org/10.1080/23279095.2019.1570928

Zahodne, L. B., Ajrouch, K. J., Sharifian, N., \& Antonucci, T. C. (2019). Social relations and age-related change in memory. Psychology and Aging, 34(6), 751-765. https://doi.org/10.1037/pag0000369

Fahri Özsungur. Adana Alparslan Türkeş Science and Technology University, International Trade and Finance (Turkey)

Contact Address: fahri.ozsungur@hacettepe.edu 